\title{
National Innovation Demonstration Zones Leading China's Regional Development
}

\author{
Xiaopei Gao, Wei Song, Xiaobao Peng \\ School of Public Affairs, University of Science \& Technology of China, Hefei, China \\ Email: gxp0406@mail.ustc.edu.cn
}

Received 19 June 2015; accepted 24 October 2015; published 27 October 2015

Copyright (C) 2015 by authors and Scientific Research Publishing Inc.

This work is licensed under the Creative Commons Attribution International License (CC BY). http://creativecommons.org/licenses/by/4.0/

(c) (i) Open Access

\begin{abstract}
This paper had studied " $3+1$ " National Innovation Demonstration Zones (NIDZ) in China, which located in Beijing, Wuhan, Shanghai and Anhui province. There were national level instructions for innovation demonstration zones. These 4 regions would benefit from the specific policy approved by the Chinese government and the whole nation depended on them to improve creative $S$ $\&$ T level in the future from "Made in China" to "Created in China". This paper had compared different aspects among these 4 innovation zones. The "1" Anhui Hefei-Wuhu-Bengbu area (HWB) would benefit from experience made by the " 3 " earlier innovation zones.
\end{abstract}

\section{Keywords}

National Innovation Demonstration Zone (NIDZ), Regional Development, Independent Innovation, Technology Transfer

\section{Brief Introduction to National Innovation Demonstration Zone (NIDZ)}

National Innovation Demonstration Zone (NIDZ) was approved by the Chinese government to promote independent innovation and development of high-tech industry in pioneering trial. They were demonstration areas to explore experience. The reason of building national and regional innovation system was to make promotions in the high-tech industry, which had played an important task to lead the economic development. Up to 2012, a total of four national innovation demonstration zones were approved by the Chinese government. They were Beijing Zhongguancun, Wuhan East Lake High-tech Zone, Shanghai Zhangjiang National Innovation Demonstration Zone, and Hefei-Wuhu-Bengbu (HWB) Comprehensive Reform Pilot Area for Independent Innovation. HWB innovation zone, following with Beijing Zhongguancun, East Lake in Wuhan, Shanghai Zhangjiang demonstration zone, became a sequence of " $3+1$ " experiment and demonstration area which included in the national 12th 5-year science and technology development planning and national independent innovation construc- 
tion plan.

The NIDZ, compared with other economic development zones or business parks, owned a lot of unique policy to support the autonomy and pilot. For example, through equity incentive pilot, NIDZ would deepen the financial reform of scientific and technological innovation pilot, support a new industry organization to participate key scientific and technological projects and organizations such as the preparation of the development plan [1]. China was going to enhance the capability of independent innovation and find the path to promote the rapid development of economy and society by exploratory means in such a new national era.

\section{Basic Information for the " $3+1$ " NIDZs}

\subsection{Zhongguancun-Industry-University-Institution Alliance}

The Zhongguancun National Demonstration Zone dates back to the "Zhongguancun Electronics Street" in the early 1980s. In May 1988, the government approved the establishment of the Beijing New Technology Industrial Development Trial Zone (predecessor of the Zhongguancun Science and Technology Park). Thus Zhongguancun became the first high-tech park in China.

On March 13, 2009, the government approved the construction of the Zhongguancun National Demonstration Zone, and made the plan to build Zhongguancun an S \& T innovation center with a global influence. Later the Development Plan Outline for Zhongguancun National Demonstration Zone (2011-2020), was launched by the government on Jan 26, 2011, marking a new starting point for Zhongguancun's development.

Zhongguancun is one of the "innovation and entrepreneurial base for overseas talents" conferred by the Central Personnel Work Coordination Group. There are more than 5000 enterprises with at least 15,000 overseas returnees. The entrepreneur representatives include Lenovo president Liu Chuanzhi and Li Yanhong, president of Baidu, and Kai-Fu Lee, Google Greater China's former CEO and the president of Innovation Works.

During the past two decades, Zhongguancun has gathered nearly 20,000 high and new-tech enterprises, represented by Lenovo and Baidu, and has formed a high and new-tech industrial cluster featuring electronic information, biomedicine, energy and environmental protection, new materials, advanced manufacturing, aerospace, R \& D and service.

Zhongguancun is the most intensive scientific, education and talent resource base in China. It boasts almost 40 colleges and universities like Peking University and Tsinghua University, more than 200 national (municipal) scientific institutions such as the Chinese Academy of Sciences and the Chinese Academy of Engineering, 67 state-level laboratories, 27 national engineering research centers, 28 national engineering and technological research centers, 24 university S \& T parks and 29 overseas student pioneer parks.

According to these advantages, Zhongguancun owns a special and most vigorous cooperation model for Industry-University-Institution Alliance. (1) Joint Laboratories or Research Centers. Joint labs or research centers would enrich the technology innovation investment from corporations to universities and research institutes. Meanwhile, this kind of cooperation would make academic research closer to markets and short product circle. These labs or research centers would also cultivate more talented researchers for both industries and academies. For example, the Sohu-Tsinghua joint lab for internet searching technology. (2) National Fund Key Projects. The government continuously encourages corporations' innovation activities which attract universities and institutes to join cooperative projects funded by national S \& T strategy. (3) University or Institution Affiliated Corporations. Innovation companies affiliated or started by universities or research institutes are the most important pattern to deal with technology transfer and I-U-I alliance. (4) Industry Alliance to define standards. Several leading companies can join together to define industrial standards and conquer technology barriers. They would accomplish joint technology innovation, take the risks, and share the interests. (5) S \& T Park and Incubator. University S \& T Park and Incubator would provide innovation-oriented companies a crucial survival environment. They would provide vital supports for these companies during their developing period. (6) Talented People. Zhongguancun National Demonstration Zone offer post doctor positions in corporations to encourage scientists interflow between both companies and research facilities. (7) International Cooperation. International elements are now attending the Industry-University-Institution Alliance. Multiple international companies settle research center in the innovation zone. Like the IEEE and UNESCO.

\subsection{Wuhan East Lake-To Gather Innovation Source by Urbanization}

Wuhan East Lake High-tech Zone was established in October 1988; March 1991, the Chinese government ap- 
proved first batch of high-tech industrial development zones; 200 was approved by the former State Planning Commission and Ministry of Science and optoelectronic industry base for the country (i.e. "Optics Valley of China”); since 2006, was approved by the relevant state ministries and nation service outsourcing base cities for the demonstration area, national biological industrial base, national science. Wuhan East Lake High-tech Development Zone was founded in October of 1988 and was approved to be the first National High-tech Industrial Development Zone by the government in March of 1991. In the year of 2001, it was approved by the government as a state-level optoelectronic industry base (Wuhan Optics Valley of China), it was admitted as a national innovation model zone by the state council.

Optics Valley of China, which is also called Wuhan East Lake High-tech Development Zone and Wuhan East Lake National Independent Innovation Demonstration area, located in the east south of Wuhan, to the south of Ezhou and to the north of Jiang Xia District. The Wuhan Hongshan District is to its west and has a common boundary with Wuchang District and East Lake Scenic Area in the north. This area is surrounded by mountains and lakes. It is a place with beautiful scenery and good environment attracting lots of talents gather here.

The planning area of Wuhan East Lake High-tech Development zone is $518 \mathrm{sq} \cdot \mathrm{km}$ and now has 500 thousands permanent population. It is home to 42 universities, 22 state key laboratories, 24 national engineering technology centers, 56 national scientific research institutes, about 700 scientists.

Wuhan East Lake High-tech Development Zone is going to build a functional city with the foundation of Optics Valley of China. The place would fulfill with vitality, efficiency, humanities, harmony. The mission of East Lake Zone is going to build a combined, independent city [2]:

City of evolvement: To gather talented people and leading the $S$ \& T cutting edge;

City of elegance: To be human oriented. The city is going to fulfill the human basic needs of physical, metal, social and other areas and provide enough facilities also good environment;

City of ecology: To develop in accordance with eco-system standards which including natural, social, cultural and economical environment;

City of efficiency: To operate and manage highly effective modern transportation that supports the urbanization.

There would be "An intellectual core", "two-commerce service center", and "functional structure of four clusters" to improve the East Lake High-tech Zone scientific research and education, industry, housing, recreation, commerce functions.

\subsection{Zhangjiang-Advanced Technology Transfer from Foreign Companies through Global Channel}

Zhangjiang High-tech Industrial Development Zone was among China's first batch of national high-tech industry development zones, and is the third indigenous innovation demonstration zone approved by the government in 2011. Its present planned area covers 42 square kilometers comprising of "one zone and six parks"; its future planned area covers 296.4 square kilometers comprising of "one zone and thirteen parks". At present, Shanghai Zhangjiang High-tech Industrial Development Zone has gathered about 30,000 enterprises (of which 300 are among the fortune 500), and more than $1000 \mathrm{R} \& \mathrm{D}$ institutions.

After 20 years of development, Shanghai Zhangjiang High-tech Industrial Development Zone has formed a cluster of seven key industries including new generation of information technology, advanced equipment manufacturing, bio-tech, new energy and new material, energy saving and environmental protection as well as automobile. Meanwhile, in the Zone are located 23 industry bases, and five largest characteristic industrial R \& D bases in China—namely, the largest R \& D bases of integrated circuit, software design, bio-medicine, culture and creativity, and financial services.

As the most concentrated place of domestic and foreign R \& D centers, 59 technology business incubators had been located in Zhangjiang, of which 18 are ratified as national level ones. There are also public service platforms around the industries, including $\mathrm{R} \& \mathrm{D}$, testing, equipment sharing, computing and other platforms around financing, training, human resources, policies, corporate culture, intellectual property rights, audio-visual and other areas. 196 public service platforms are established.

In the context of globalization, foreign-funded enterprises/foreign companies, especially multinational corporations become the main force of the international technology transfer. The majority of developing countries, the government is regarded FDI as a major way to learn and upgrade their knowledge/technology base from foreign 
companies [3].

Why Zhangjiang been favored by foreign-funded R \& D institutions? The competitiveness mainly from three aspects: (1) Policies attractiveness, the Shanghai municipal government issued the "Focus on Zhangjiang" strategy; (2) Industrial agglomeration lead to R \& D gathering Zhangjiang Park through the promotion of the industry chain development mode, in a relatively short period of time, in the field of integrated circuits, software, bio-pharmaceutical, and other industries quickly realize hungry and foreign enterprises gathered to form a powerful industrial groups; (3) Third, is to build a comprehensive research and development services, primarily to build a technology platform and service platform, to strengthen personnel training. Zhangjiang is now owns the new national R \& D institutions of the National Human Genome Research Center, the National Center for Drug Screening, National Drug Safety Evaluation Center, Shanghai Light Engineering Center, Shanghai Supercomputing Center. They, along with GE, DuPont, Honeywell, Solomon Haas multinational R \& D centers, jointly develop the technology platform of the highest level of the park.

\subsection{Hefei-Wuhu-Bengbu (HWB) - Industrial Transfer + Independent Innovation}

The 3 Cities in Anhui Province called Hefei-Wuhu-Bengbu (HWB) are three important industrial centers, respectively, corresponding to the "The Middle Anhui", "The South Anhui", and "The North Anhui" these three regions. They play a strong polarization and radiation effect. As the leading area for regional development, enhancing the regional independent innovation ability for HWB area is significantly important.

The Independent Innovation relies on human resource supports. The three cities of Hefei, Wuhu and Bengbu own University of Science and Technology of China, Hefei Industry University, Anhui University, Chinese Academy of Sciences, Hefei Branch Research Institute, more than 130 universities and research institutes, six National Engineering Research Centers. Also Hefei was the only technological innovation pilot municipality in China.

The HWB zone aims to relocate Pan-Yangtze River Delta industries and to active science and technology advantages, to build research alliances with the Yangtze River Delta. Reform pilot area of HWB is mainly becoming the starting point and the first integration of the Yangtze River Delta, through comprehensive reform, optimize the environment, and strengthen their own. At the same time, to establish research alliances with the Yangtze River Delta, co-integration of scientific and technological resources, to further strengthen in energy, information technology, bio-medicine, major equipment manufacturing, and other areas of cooperation, jointly organized by the core technology research. HWB innovation reform area would undertake the transfer of hightech industries in the Yangtze River Delta as well as build a demonstration zone.

\section{The Developments Patterns of Innovation Demonstration Zones}

The approval of 4 national innovation demonstration zones, Zhongguancun, Donghu, Zhangjiang and HWB, is aimed to explore new innovation paths for economy growth. These four zones, which are located in different districts and share distinct developing routes, have their own plans through success. In this chapter, the patterns and characteristics of the innovation development path of the 4 zones would be analyzed through the following 4 aspects: basic status, leading industries, personnel acquisition, and financial environment.

\subsection{Basic Status}

The GDP value and the quantities of enterprises, universities, colleges, research institutions and laboratories could represent the current developing status and the allocation of innovation resources in these zones (Table 1).

From what have been shown in Table 1, Zhongguancun's GDP value has reached 1960 billion RMB in 2011, much higher than the other 3 zones. A large portion of top universities and research centers located in this area, such as Tsinghua University, Peking University and the Chinese Academy of Science, which had made great contribution to the innovation capacity growth in Zhongguancun. Compared with Zhongguancun, there are also numerous universities and labs in Donghu. However, the GDP of Donghu in 2011 was much lower than the other innovation zones due to its single optoelectronic-information-industry-centered developing mode. And Wuhan, the location of Donghu zone, is in the central region of China, which had disadvantages in absorbing foreign investment and vulnerable to the domestic economic change, had gone through the pressures in cost increase and financial depressions. Zhangjiang, whose domestic innovation resources is not as much as the other 
Table 1. Basic Information of the 4 zones.

\begin{tabular}{|c|c|c|c|c|c|c|c|}
\hline & $\begin{array}{c}\text { Area } \\
\text { (kilometers) }\end{array}$ & $\begin{array}{c}\text { GDP } \\
\text { (Billon RMB) }\end{array}$ & Enterprises & $\begin{array}{l}\text { Universities/ } \\
\text { Colleges }\end{array}$ & $\begin{array}{c}\text { Research } \\
\text { Institutions }\end{array}$ & Labs & Leading Industries \\
\hline Zhongguancun & 232 & 1960 & 20,000 more & 41 & 200 more & 122 & $\begin{array}{l}\text { Electronic information } \\
\text { Biomedicine } \\
\text { Energy and environment } \\
\text { New materials } \\
\text { Advanced manufacturing } \\
\text { Aviation and aerospace }\end{array}$ \\
\hline Donghu & 224 & 381 & 30,000 more & 48 & 56 & 21 & $\begin{array}{l}\text { Optoelectronic information } \\
\text { Bioengineering and biomedicine } \\
\text { Environmental protection } \\
\text { Mechatronics } \\
\text { High-tech agriculture }\end{array}$ \\
\hline Zhangjiang & 296.4 & 823.18 & 30,000 more & 11 & 3 & 292 & $\begin{array}{l}\text { Biomedicine } \\
\text { Electronic information } \\
\text { Cultural and creative } \\
\text { Aviation and aerospace } \\
\text { Advanced manufacturing } \\
\text { Automobiles and auto parts }\end{array}$ \\
\hline HWB & 16,281 & 833 & 1000 more & 29 & 199 & 61 & $\begin{array}{l}\text { Electronic information } \\
\text { Energy and environment } \\
\text { New energies } \\
\text { Bioengineering } \\
\text { Advanced manufacturing } \\
\text { New energy automotive } \\
\text { New materials } \\
\text { Public safety production }\end{array}$ \\
\hline
\end{tabular}

Note: dates in Table 1 represent the situation in 2011. The quantities of labs include national labs, provincial labs and those established with enterprises or companies. The GDP value and quantities of enterprises in HWB only comprises the identified high-tech companies in this area. Data resource: the website of 4 pilot areas.

innovation zones, had explored a new way through success: inviting the R \& $\mathrm{D}$ institutions of international companies to establish new research centers in Zhangjiang. Some companies and institutions in Zhangjiang are in the Fortune 500 list, which had brought in high competitive capacity to this area. HWB, the youngest innovation zone, had acquired quite a lot of innovation resources, but the output income of this region is still not very promising considering its huge land area.

\subsection{Leading Industries}

The leading industries of these 4 regions could be observed from their developing plans drafted by the government department. Table 1 had listed the leading industries that domestic government are intended to support, which mostly belong to the strategic emerging industries that the national government had proposed as priority. Figure 1 is a summarizing picture of leading industries in 4 innovation zones. Some of the 6 leading industries in Zhongguancun, including electronic information, biomedicine, energy and environment, new materials, Advanced manufacturing, aviation and aerospace, are also in the industry plans for the other 3 zones. Most of the planned leading industries share common factors among the 4 regions. With mechatronics and High-tech Agriculture Industry in Donghu, cultural and creative and automobiles and auto parts in Zhangjiang, new energy automotive and public safety production industry in HWB, the 4 innovation zones had also targeted in some different areas.

\subsection{Personnel Acquisitions}

Talents, especially the leader persons in a field, are a kind of scarce resources. Lack of the senior technology talents is serious problems for almost high-technology development zone, and those that successfully attract and retain talents can get long last development future. Therefore, many cities and regions introduce all kinds of preferential policies to attract talents. Zhongguancun, Donghu, Zhangjiang, HWB innovation zone have their respective policies: 


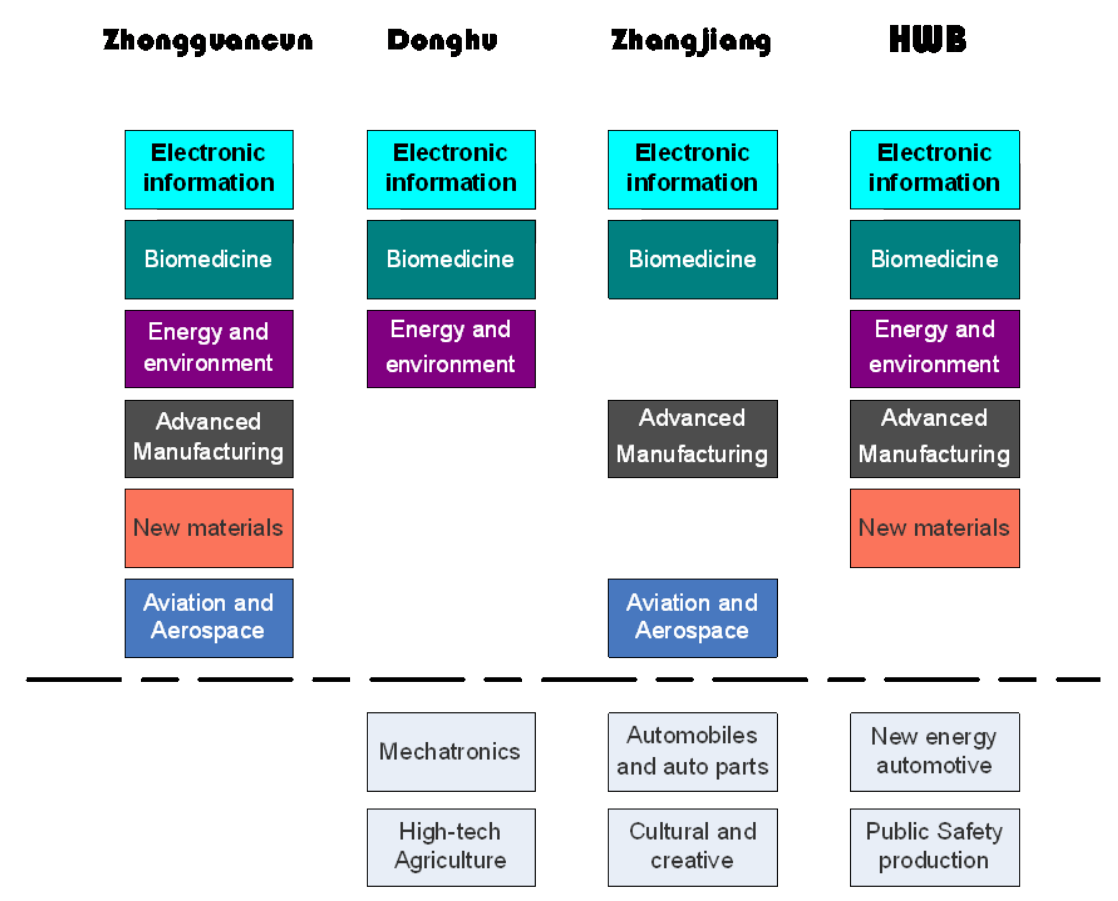

Figure 1. Leading industries of 4 innovation zones.

\section{(1) Zhongguancun}

Zhongguancun gets the preferential policies focused on "high-leading talents gather program" which mainly put out towards talents. The project sets a high standard for talent's being getting sponsored. Zhongguancun wishes they could gather experts, scholars from abroad universities and other high-tech persons with rich practical experience. Those who get S \& T innovation talent, venture capitalist or S \& T intermediary talent will get one million RMB as a lump-sum award, and also a $80 \%$ reduction of pre year local taxes.

\section{(2) Zhangjiang}

The talent policy of Zhangjiang demonstration zone involves 2 parts [4]. The First part of this policy is to improve the basic living and working conditions for personnel, including the implementation of low-cost housing project, resolving the studying and household registering problems for company staffs and their families, the health-care insurance spread and so on. This approach is to keep the basic and middle level staffs to start career in Zhangjiang. Another part of policy is through the "Zhangjiang Talent" award, which was held to spirit leading talents to make contribution to corporations and parks. Most of the winner could receive a 500 thousand or 1 million RMB check for their contributions. This award is to attract leading talents to serve in the innovation zone.

\section{(3) East Lake}

The talent policy of Donghu demonstration area mainly reflects in "3551 talent policy", which refers in the next three years, Donghu high-tech zone takes high-tech industrialization as the theme and the overseas highlevel talents as the key point. In optoelectronic information and the other four key industry field, Donghu will introduce and train about 50 leading talents, who shall master international leading technology and lead industry development. At the same time, Donghu will introduce and train about 1000 high-level talents, who engage in scientific and technological innovation, achievements transformation and technological venture. "3551 talents project" is a policy, which attracts urgent and high-tech entrepreneurial talents through the significant cash incentives. "3551 talents project" provides the entrepreneurial team maximum grand to 100 million Yuan and provides individual maximum grant to 5 million. Besides, there are housing and living subsidies. Donghu demonstration area provides a huge privilege policy and financial support in attracting talents.

(4) HWB

HWB demonstration area supports affirmatory technical leading talents through establishing pecial funds for talent mass item in strategic emerging industries [5]. According to the needs of HWB independent innovation synthetically testing district, management department draw up 36 innovative talent projects, provide 10 million 
Yuan project funds and give the outstanding contributors RMB 200 thousand bonuses [6]. Compared to other demonstration areas, the financial support in attracting talents of HWB demonstration area is smaller (Table 2).

\subsection{Financial Environment}

Capital is a crucial factor to the development of start-up companies, especially in high-tech industries. The Industrialization process involves great amount of incomes. Therefore, the financial environment of high-tech parks took an important role in the further development of the zones. In the issue of improving financial environment, Zhongguancun is definitely the leading park in the national area. Zhongguancun's experiences in high-tech financial integration and the implementation of multiple financial instruments had become a success mode for other regions to follow. The main reason for the establishment of other 3 innovation zones is to implement the "Zhongguancun Financial Mode" to these regions and, if succeed, to take this mode in other less developed areas.

The Zhongguancun financial mode consists of 3 parts [3]:

(1) The inner-park credit system

The inner-park credit system was proposed by Zhongguancun management committee. The main function of this system is to gather information and provide credit rating reports for SMEs to apply loans from banks or guarantee agencies. This system was a supplement for the banking credit system, which intends to give lower credit rates to small-sized and start-up companies. Owing to the application of inner-park credit system, most small but potential companies could get enough loans in the financial system. The inner-park credit system mode have been implemented and spread to other innovation zones and parks.

(2) Multiple investment channels

The investment and financing channels for enterprises in Zhongguancun had been expanded due to series policies that intend to promote the enterprises performance in this area. The traditional credit loan system had spread its range to most companies. There are also other financial solutions to loans such as intellectual property pledge loans, credit insurance, trade finance, micro-credit loan.

VE, PE and angle investors are another crucial channel for companies who need large amount of investment. In these years, a large number of venture capital institutions, 100 more, had set up headquarters or branches in Zhongguancun, who had controlled more than 20 billion RMB. The data from the CMC showed that 1/3 venture investment cases and incomes were invested to companies in Zhongguancun in the recent 5 years. To attract venture capital invest in the park, the CMC had formed their own venture guidance capital fund and created a mechanism to subsidize the risks in the investment.

The "Zhongguancun agency share transfer system", known as the new 3rd board nowadays, is a crucial capital market for SMEs to acquire investment. This transfer system was firstly an experimental thing for Zhongguancun companies to solve their financial problems. Now this capital market had achieved great success and was to spread in other 3 innovation regions. There are a large portion of companies had listed on Nasdaq, NYSE, HKE \& CL and other foreign capital markets. The training and counseling work by the CMC had greatly accelerated their process of IPO.

(3) Specific financial franchisees in park

The specific financial franchisees of banks and other financial institutions could provide services that could well fit the status and need of companies in Zhongguancun. A large number of banks had held franchisees in Zhongguancun, such as Bank of Beijing, Bank of Communication, Bank of China, and the Small Enterprise Credit Center of China Merchant Bank. These franchisees were especially designed for Zhongguancun companies and could lift their risk tolerance, optimizing the loan approval process and other ways to improve the financial efficiency.

Table 2. Comparison of personnel supporting policies in 4 zones.

\begin{tabular}{ccccc}
\hline & Supporting Amount & Supporting Range & Specific Targets & Rewards \\
\hline Zhongguancun & High & Small & Leading Talents & To Individuals \\
Donghu & High & Small & Leading Talents & To Projects \\
Zhangjiang & Low \& High & Large & Ordinary \& Leading Talents & To Individuals \\
HWB & Low & Small & Leading Talents & To Projects \\
\hline
\end{tabular}


In October 2012, the National Development and Reform Commission, the Department of Science and Technology, the Securities Regulatory Commission, and the other six ministries, and commissions together with the Beijing Municipal Government jointly issued "Opinion of Constructing National Technology and Finance Innovation Center about Zhongguancun National Independent Innovation Demonstration Area”. Thus, the status of Zhongguancun was established as the national technology and finance innovation center. The other three demonstration areas are still in the primary stage in the field of innovation of investment and financing. The "Zhongguancun model" is the main goal of the financial innovation reformation of the other three demonstration areas.

\section{Summary}

National innovation demonstration zone was approved by the Chinese government. The reasons were found that the whole nation was eager to develop independent innovation system to make products from "Made in China" to "Created in China".

There were major differences among these 4 innovation demonstration zones. As we mentioned, their level of development, industry navigation, human resource policy, investment and financial environment, these 4 aspects performed a certain degree of difference which made by their own characters. The origin of these innovation demonstration zones was different among history, local policy, advantages and disadvantages.

The government approved the " $3+1$ " model for innovation development to accelerate creativity in the whole nation. The 3 demonstration zones were founded earlier than the one we called Hefei-Wuhu-Bengbu (HWB) demonstration area. As a result, there would be plenty of former success to learn for HWB demonstration zone. The Industry-University-Institution Alliance, FDI investment and technology transfer, urbanization in demonstration zone, they were good experience for HWB.

Meanwhile, there were advantages in HWB zone. USTC and CAS branch in Hefei were leading scientific research centers in China as well as the whole world. They also brought up talented young guys to support the national development. The HWB zone played an important role in technology transfer among Pan-Yangtze River Delta industries [7]. Companies in HBW would cost much less compared to developed areas in Pan-Yangtze River Delta. One more advantage was that HWB had a vast geographical development potential with the fifth-largest freshwater lake, Chaohu Lake.

\section{Acknowledgements}

This work was supported by the Soft Science Research Project of Anhui Province (No.1402052002) and Key Project of Humanities and Social Sciences of the Education Department of Anhui Province (No. SK2014A078).

\section{References}

[1] Fu, S.Q., et al. (2009) The Construction and Development of the Core Area of the National Independent Innovation Demonstration Zone and Cooperative System. China University Science \& Technology, 8, 42-47. (In Chinese)

[2] Hu, X.L., et al. (2007) Wuhan East Lake High-Tech Zone Construction and Development Mode Based on Competitive Advantage Method. Science \& Technology Progress and Policy, 24, 60-64. (In Chinese)

[3] Ai, S.W., et al. (2009) The Regional Differences of Technological Learning: Zhongguancun vs. Zhangjiang. Science of Science of Science and Management of $S \&$ T, 5, 40-46. (In Chinese)

[4] Wu, K., et al. (2012) Independent Innovation Policy and Its Application Research in Zhangjiang National Demonstration Zone. Science \& Technology Progress and Policy, 29, 98-102. (In Chinese)

[5] Xu, M., et al. (2012) The Problem of Hefei-Wuhu-Bengbu Innovation Demonstration Zone Development and Policy Analysis Contemporary Economics. Contemporary Economics, 9, 102-103. (In Chinese)

[6] Wang, Y.B., et al. (2012) Hefei-Wuhu-Bengbu Innovation Experiment. Decision Making, 9, 13-15. (In Chinese)

[7] Qiu, J.H., et al. (2009) Investigation Report for Anhui Province to Participate in the Pan-Yangtze River Delta on the Division of Labor and Industries Relocation. Counselors' Office of the State Council. 